\title{
Sensorial Comfort/Discomfort of Lingerie Based on Hand Assessment and Objective Evaluation
}

\author{
Sachiko Sukigara ${ }^{* 1}$,Takako Fujimoto ${ }^{* 2}$, and Masako Niwa ${ }^{* 3}$ \\ *1 Faculty of Education, Niigata University, Igarashi, Niigata, 950-21 Japan \\ * 2 Hokkaido University of Education. Iwamizawa, Hokkaido, 068 Japan \\ ${ }^{*}$ Faculty of Home Economics, Nara Women's University, Kitauoya-Nishimachi, Nara, 630 Japan
}

\begin{abstract}
The purpose of this study was to determine the relationship between subjective assessments of overall sensorial comfort and bipolar hand attributes, and to predict subjective values with mechanical, surface and thermal characteristic values of lingerie fabrics. The tactile sensation of test samples was evaluated by consumers using the bipolar word pairs. A strong dependence of overall sensorial comfort on fab. ric soft/hard, smooth/rough and rigid/drapable was observed. Distribution of mechanical properties for these lingerie fabrics was rather smaller than that of women's thin dress fabrics. Therefore, heat, water, and air transmission properties, and surface characteristcs of fabrics were important parameters for the prediction of sensorial comfort of lingerie fabrics.
\end{abstract}

\section{Introduction}

Comfort or discomfort is important in the acceptance or rejection of clothing by the consumer. There are various stimuli that cause a person to feel discom fort. Thus, the perception of comfort is a complex phenomenon. The concept of comfort includes thermal comfort and tactile comfort, which may be related to the mechanical property of fabrics, heat, moisture and air transmission through fabrics, and garment construction. Psychological and physiological factors also affect the total assessment of whether clothing is judged comfortable or uncomfortable.

Physiological comfort has been studied in terms of skin and core temperature changes and perspiration rate, in the controlled limited environment $(1,2]$. Per ceived comfort has been also studied extensively by the subjective wearing test $[3,4]$ and related physi. cal measurements. Demartino et al. $[5,6]$ extensively studied the perceived comfort of polyester fabrics from both objective and subjective tests. They concluded that objective tests were useful to predict general comfort trends, but that, they could never be used as a replacement for well planned and well ex. ecuted subjective wearer trials.

Fairly limited works reported the relationship be- tween physiological comfort and fabric property. Hoscheke [7] considered two aspects which related to clothing comfort, they were prickliness and warmth. Garnsworthy et al. [8] studied mechanisms in cutaneous sensations of prickle and itch evoked by wool fabrics from the skin comfort point of view. They indicated that the major irritant features of wool fab. rics were protruding fiber ends capable of bearing loads of approximately $100 \mathrm{mg}$ or more.

Kawabata [9] developed an objective measurement of fabric hand which evaluates mechanical and tactile comfort. In his research, hand assessments are based on tactile sensations caused by a fabric's mechanical and surface properties.

In this paper, we only focussed on tactile sensation of comfort/discomfort of lingerie fabrics. We assume that the final judgment of tactile comfort is based on the suitability of the mechanical and surface properties for the use in a particular season. In that sense, the objective evaluation of fabric hand [9] can be ap. plied to the evaluation of sensorial comfort of linge. rie.

The objective of this work was to determine the relationship between the results of the judgment of tactile tests by using bipolar word pairs most highty correlated with bipolar comfort/discomfort assess. 
ment and mechanical, surface and thermal character. istic values of selected lingerie fabrics.

\section{Experimetal}

\subsection{Samples}

The samples used for this study were thirty six

Table 1 Samples

\begin{tabular}{|c|c|c|c|c|c|c|}
\hline & Fibers & Structure & & & & Thickness \\
\hline & & & $\begin{array}{l}\text { Wales } \\
\left(\mathrm{cm}^{-1}\right)\end{array}$ & $\begin{array}{l}\text { Course } \\
\left(\mathrm{cm}^{-1}\right)\end{array}$ & $\left(\mathrm{mg} / \mathrm{cm}^{2}\right)$ & $(\mathrm{mm})$ \\
\hline $\mathrm{T} 1$ & polyester & tricot jersey & 26 & 22 & 8.83 & 0.367 \\
\hline $\mathrm{T} 2$ & polyester & tricot jersey & 22 & 26 & 9.43 & 0.364 \\
\hline $\mathrm{T} 3$ & polyester & tricot jersey & 21 & 25 & 14.76 & 0.404 \\
\hline $\mathrm{T} 4$ & polyester & tricot jersey & 21 & 26 & 9.13 & 0.319 \\
\hline $\mathrm{T} 5$ & polyester & double tricot & 20 & 19 & 8.95 & 0.322 \\
\hline T6 & polyester & tricot & 24 & 19 & 8.51 & 0.693 \\
\hline $\mathrm{T} 7$ & polyester & tricot crepe & 17 & 28 & 9.82 & 0.895 \\
\hline $\mathrm{T} 8$ & polyester & tricot crepe & 18 & 24 & 9.64 & 0.983 \\
\hline T9 & polyester & tricot crepe & 19 & 20 & 12.68 & 0.948 \\
\hline T10 & polyester & tricot satin & 16 & 19 & 9.39 & 0.388 \\
\hline $\mathrm{T} 11$ & polyester & tricot matelasse & 36 & 19 & 7.89 & 1.062 \\
\hline $\mathrm{T} 12$ & polyester & tricot jersey & 28 & 24 & 8.29 & 0.339 \\
\hline $\mathrm{T} 13$ & polyester & tricot jersey & 22 & 30 & 9.70 & 0.583 \\
\hline T14 & polyester & tricot jersey & 25 & 23 & 8.34 & 0.425 \\
\hline $\mathrm{T} 15$ & polyester & tricot crepe & 27 & 20 & 11.42 & 0.517 \\
\hline $\mathrm{T} 16$ & polyester & plain knit & 33 & 27 & 9.51 & 0.324 \\
\hline $\mathrm{T} 17$ & polyester & plain knit & 22 & 18 & 14.79 & 0.703 \\
\hline T18 & polyester & plain knit & 41 & 25 & 12.81 & 0.487 \\
\hline $\mathrm{T} 19$ & polyester & plain knit & 21 & 24 & 9.71 & 0.339 \\
\hline $\mathrm{T} 20$ & polyester & plain knit & 22 & 24 & 11.36 & 0.396 \\
\hline $\mathrm{T} 21$ & polyester & plain knit & 49 & 22 & 11.33 & 0.319 \\
\hline $\mathrm{T} 22$ & polyester & plain knit & 49 & 31 & 10.36 & 0.304 \\
\hline $\mathrm{T} 23$ & polyester & plain knit & 38 & 27 & 11.64 & 0.485 \\
\hline $\mathrm{T} 24$ & polyester & plain knit & 13 & 11 & 10.19 & 0.725 \\
\hline $\mathrm{T} 25$ & silk & plain knit & 25 & 19 & 5.66 & 0.260 \\
\hline $\mathrm{T} 26$ & $\begin{array}{l}\text { acetate } 70 / \\
\text { nylon } 30\end{array}$ & plain knit & 41 & 24 & 11.10 & 0.441 \\
\hline $\mathrm{T} 27$ & $\begin{array}{l}\text { polyester } 70 / \\
\text { cotton } 30\end{array}$ & plain knit & 25 & 14 & 8.98 & 0.595 \\
\hline $\mathrm{T} 28$ & cupra & tricot jersey & 25 & 20 & 10.14 & 0.351 \\
\hline $\mathrm{T} 29$ & nylon & tricot jersey & 46 & 23 & 8.73 & 0.302 \\
\hline $\mathrm{T} 30$ & silk & plain knit & 16 & 19 & 7.74 & 0.321 \\
\hline T31 & cotton & plain knit & 15 & 27 & 13.28 & 0.792 \\
\hline \multirow[t]{2}{*}{$\mathrm{T} 32$} & $\begin{array}{c}\text { polyester } 34 / \\
\text { cotton } 66 \\
\end{array}$ & plain knit & 11 & 13 & 14.03 & 1.537 \\
\hline & & & $\begin{array}{l}\text { Ends } \\
\left(\mathrm{cm}^{-1}\right)\end{array}$ & $\begin{array}{l}\text { Picks } \\
\left(\mathrm{cm}^{-1}\right)\end{array}$ & & \\
\hline $\mathrm{T} 33$ & polyester & satin woven & 42 & 42 & 10.08 & 0.270 \\
\hline $\mathrm{T} 34$ & polyester & satin woven & 130 & 47 & 9.79 & 0.293 \\
\hline $\mathrm{T} 35$ & silk & satin woven & 96 & 52 & 8.73 & 0.264 \\
\hline T36 & cotton & lawn woven & 40 & 33 & 7.00 & 0.423 \\
\hline
\end{tabular}




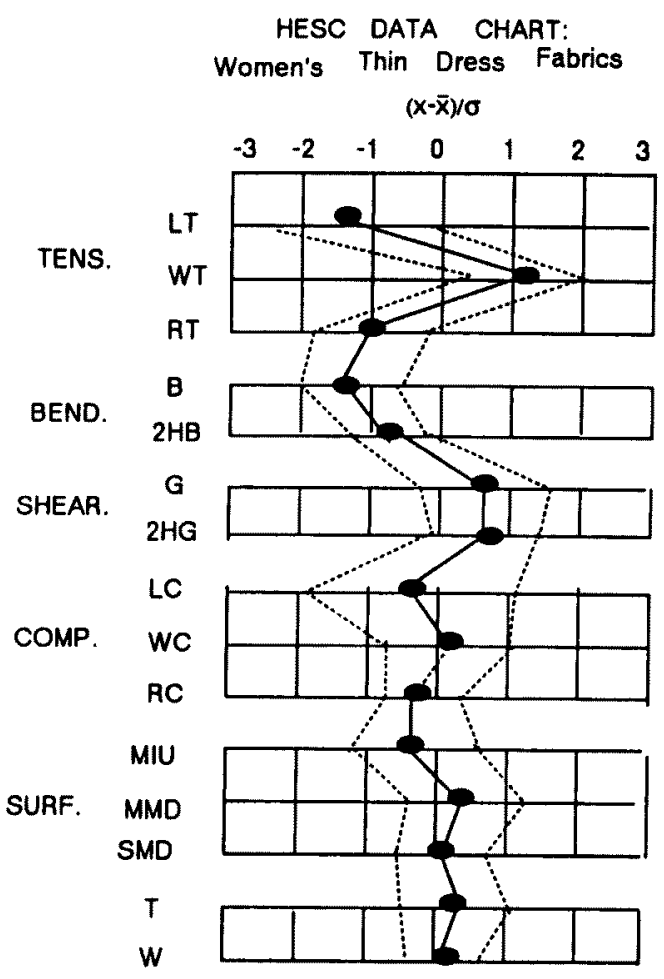

Fig. 1 Comparison of the mean (-) - and standard deviation $(\cdots)$ for the 36 lingerie fabrics and women's thin dress fabrics.

commercially produced lingerie fabris: 26 polyester, 1 nylon, 1 cupra, 3 silk, 2 cotton, 2 cotton/polyester blended fabrics, and 1 acetate/nylon blend. The knitted structure for lingerie is commercially popular, thus thirty-two of the fabrics were knitted and only four fabrics having different fiber type were woven. Details of samples are shown in Table 1.

The Hand Evaluation and Standardization Commit. tee (HESC) in Japan has developed a system of stand. ardization for women's thin dress and underwear fabrics $[9,10]$. Mechanical and surface properties for fabrics were measured using a KES-F system [9] at $20^{\circ} \mathrm{C}, 65 \% \mathrm{RH}$ and characteristic values of tensile, bending, shear, compression and surface properties were calculated (see APPENDIX A). In Fig. 1, the mean of 36 samples for the mechanical and surface properties are plotted in the data chart [9] for the women's thin dress woven fabrics (mean weight: 9.17 $\mathrm{mg} / \mathrm{cm}^{2}$ : standard deviation: $1.50 \mathrm{mg} / \mathrm{cm}^{2}$ ). Mean $(\bar{X})$ and standard deviation $(\sigma)$ in the chart are obtained from 120 commercially produced fabrics in Japan. The broken line indicates the standard deviation for each of the mechanical and surface properties for lingerie fabrics used in this study. It is seen that the mechanical properties of lingerie fabrics are in the same range as those of women's thin dress fabrics with the exception of tensile and bending properties. The difference in tensile and bending properties arises because the lingerie fabrics are mainly knitted.

\subsection{Hand Assessment}

The survey was conducted in two seasons. The first survey was carried out in the summer from June to August 1989 with 76 women participants and the second survey in the winter from November to December 1989 with 86 women participants who were a different group of people from the previous survey. Three of the fabrics (silk; T30, cotton; T31, polyester/cotton blend; T32) were used only for the winter survey. The subjects were in the $18-30$ age range, and included University students aged 18 to 23 making up $61 \%$ of all subjects.

Assessments were carried out in the laboratory. Temperature and $\mathrm{RH}$ in the room was $25 \pm 1.6^{\circ} \mathrm{C}$, $62 \pm 4.7 \% \mathrm{RH}$ in the summer and $20 \pm 2.4{ }^{\circ} \mathrm{C}, 45 \pm$ $4.4 \% \mathrm{RH}$ in the winter time.

The semantic differential grid was made according to the following procedure. We first used 15 pairs of adjectives to assess the tactile characteristics of underslip fabrics [11] (viz. soft-hard, smooth-rough, cool-hot, light-heavy, fine-coarse, crisp-limp, clammyabsorbent, natural-synthetic, sheer-bulky. clingyflowing, crushable-resilient, lacy-plain, drapablerigid, scratchy-silky, stiff-soft). A preliminary experiment was carried out to present the grids to 28 female students. We selected 10 bipolar descriptors out of 15 which were understood most commonly by the students. We also added such two more (thinthick, discomfort-comfort) for the following reasons. Fabric thickness is the important fundamental characteristic which can be easily judged by hand. "Comfort-Discomfort" is the overall judgment of a fabric. The twelve bipolar descriptors were again presented to a different group of students. When a subject could not understand the meaning of descriptor, we explained the meaning. For example, "lacy" means a fan. cy. irregular or puckered surface fabric and "plain" 
indicates a fabric with little or no embellishments. "Clingy" means that a fabric clings to the body by electrostatic energy or fabric softness and the opposit meaning represents a fabric which flows or is away from the body. This property is also important to consider the wearing comfort of lingerie. Some words were changed to be more easily understandable. The final 12 bipolar fabric descriptors were soft-hard. smooth-rough, cool-warm, light-heavy, clammy-absorbent, natural-synthetic, thin-thick, clingy-flowing, crushable-resilient, lacy-plain, drapable-rigid and discomfort-comfort.

Subjects were given printed copies of the semantic differential grid as shown in Fig. 2. We then asked them to evaluate test samples $(25 \mathrm{~cm} \times 25 \mathrm{~cm})$ by hands and also put a cross $(\times)$ on the position of each scale that best described the attributes as a lingerie used in the summer when the survey was car. ried out in summer. It is essential that the subject has a clear idea of the purpose and season for which the fabric is inhended. Firstly, they were allowed to handle all fabric samples before evaluating each sample individually. Fabrics were presented in random order for judging to forestall time error [12] and to prevent judgment fatigue error. They were not told the fiber type and asked to ignore the effect of the fabric color. Actually, the color for $80 \%$ of the sam. ples were white, light saimon pink or pale yellow.

\subsection{Heat and Moisture Transmission Measurement}

Heat and moisture transimission and the transient heat flow were investigated using a KES themolabo II [13]. Heat loss was measured for four cases as fol lows. 1) a specimen is placed on the hot plate and the rate of heat loss of the hot plate measured $\left(Q_{D C}\right)$. 2) A wet paper is placed on the hot plate and the fabric specimen is placed on top of this, then the rate of heat loss of the hot plate $Q_{W C}$ is measured. 3) a $5 \mathrm{~mm}$ space is maintained between the specimen and the plate and the rate of heat loss $\left(Q_{D S}\right)$ is measured. 4) the wet paper is placed on the hot plate. A space be tween the specimen and the wet paper is maintained then the ratio of heat loss ( $\left.Q_{W s}\right)$ is measured. Effec tive thermal conductivity of a fabric $\lambda$, and heat con ductance $K^{\prime}$ are also measured. These values are con sidered to be important to predict the wearing com fort and may be reflected in the evaluation of clammy feeling. A measure of the warmth or coolness of a fab. ric surface was obtained by using the finger robot [14] and the characteristic value $C$ which represents the transient heat flow was calculated (see APPEN DIX $B$ ). Measuring condition for these parameters are listed in APPENDIX B.

\subsection{Data Analysis}

\subsubsection{Subjective Values}

We numbered from one to seven on each bipolar scale from left to right and counted extremely soft as one on the left and extremely hard as seven on the right. For each fabric sample, mean and standard de. viation values of all judgments were calculated.

\subsubsection{Stepwise Block Regression Analysis}

In order to investigate the relative influence of objective properties on the subjective values, the step wise block regression analysis was used. This tech nique has been developed and successfully used to translate mechanical data into hand values [9].

The parameters were grouped in the following seven blocks; 1) tensile, 2) shear, 3) bending, 4) compression, 5) surface, 6) mass per unit area, thickness and 7) heat, water and air transmission properties.

The average of each subjective value, $Y_{s}$ (for exam. ple softness, smoothness etc.) and the 16 mechanical data and heat, moisture and air transmission data $X_{i}$ $(i=1 \cdots 24)$ were correlated to give the linear equa tion as follows

$$
\mathrm{Y}_{\mathrm{s}}=\mathrm{C}_{\mathrm{o}}+\sum_{\mathrm{i}=1}^{24} \mathrm{C}_{\mathrm{i}} \mathrm{X}_{\mathrm{i}}
$$

where $C_{o}$ and $C_{i}$ are constants and $X_{i}$ is the deviation of the mechanical parameter from the population mean, normalized by the standard deviation, namely:

$$
\mathrm{X}_{\mathrm{i}}=\frac{\mathrm{x}_{\mathrm{i}}-\mathrm{M}_{\mathrm{i}}}{\sigma}
$$

where $x_{i}=$ values of the parameter, $M_{1}=$ mean value of $x_{i}$ for the population of 36 fabrics and $\sigma=$ standard deviation of $\mathrm{x}_{\mathrm{i}}$

Mean and standard deviation of mechanical and surface parameters are listed in Table 2. Some values were converted to the logarithmic values in order to obtain the symmetric distribution against the population mean.

Constants $C_{i}$ in equation (1) represents the contribution of parameters $X_{i}$ to subjective value $Y_{s}$. 
The prediction of overall comfort by mechanical, surface and thermal parameters was carried out using the technique developed for the objective total hand value [9]. The regression equation to obtain the value of overall comfort $Y_{c}$ consists of linear and squared terms of mechanical, surface and thermal variables.

Table 2 Mean, $M_{i}$ and Standard Deviation $\sigma_{i}$ of Mechanical, Surface, Heat and Air Transmission Properties

\begin{tabular}{|c|c|c|c|c|}
\hline & \multicolumn{2}{|c|}{ Summer $(n=33)$} & \multicolumn{2}{|c|}{ Winter $(n=36)$} \\
\hline & $\mathbf{M}_{\mathrm{i}}$ & $\sigma_{i}$ & $\mathrm{M}_{\mathrm{i}}$ & $\sigma_{i}$ \\
\hline \multicolumn{5}{|l|}{ Tensile } \\
\hline LT & 0.633 & 0.0901 & 0.640 & 0.0901 \\
\hline $\log W T$ & 0.107 & 0.2896 & 0.152 & 0.3190 \\
\hline $\mathrm{RT}$ & 51.511 & 8.3728 & 50.547 & 8.7080 \\
\hline \multicolumn{5}{|l|}{ Shear } \\
\hline $\log G$ & -0.179 & 0.2587 & -0.194 & 0.2527 \\
\hline $\log 2 \mathrm{HG}$ & 0.155 & 0.3099 & 0.153 & 0.2974 \\
\hline $\log 2 \mathrm{HG} 3$ & 0.155 & 0.3099 & 0.153 & 0.2974 \\
\hline \multicolumn{5}{|l|}{ Bending } \\
\hline $\log B$ & -2.117 & 0.2501 & -2.115 & 0.2524 \\
\hline $\log 2 \mathrm{HB}$ & -2.253 & 0.2434 & -2.239 & 0.2641 \\
\hline \multicolumn{5}{|l|}{ Surface } \\
\hline MIU & 0.211 & 0.0352 & 0.212 & 0.0358 \\
\hline $\log$ MMD & -1.569 & 0.1609 & -1.571 & 0.1565 \\
\hline $\log$ SMD & 0.512 & 0.3018 & 0.547 & 0.3131 \\
\hline \multicolumn{5}{|l|}{ Compression } \\
\hline LC & 0.690 & 0.0889 & 0.684 & 0.0902 \\
\hline $\log W C$ & -1.676 & 0.3648 & -1.651 & 0.3849 \\
\hline $\mathrm{RC}$ & 41.455 & 3.7438 & 41.556 & 4.7020 \\
\hline $\log \mathrm{T}$ & -0.354 & 0.1720 & -0.336 & 0.1929 \\
\hline \multicolumn{5}{|l|}{ Weight } \\
\hline $\log W$ & 0.991 & 0.0825 & 0.996 & 0.0876 \\
\hline \multicolumn{5}{|c|}{ Heat transmission } \\
\hline$Q_{D C}$ & 10.23 & 0.6196 & 10.14 & 0.6905 \\
\hline$Q_{W C}$ & 40.91 & 0.2031 & 40.52 & 2.4676 \\
\hline$Q_{D S}$ & 5.845 & 0.1281 & 5.839 & 0.1496 \\
\hline Qws & 19.97 & 0.4421 & 19.944 & 0.4884 \\
\hline$\lambda\left(\times 10^{-2}\right)$ & 4.43 & 0.496 & 4.46 & 0.544 \\
\hline$K^{\prime}$ & 123.2 & 38.02 & 119.9 & 38.927 \\
\hline $\log C$ & -1.522 & 0.0808 & -1.529 & 0.0805 \\
\hline \multicolumn{5}{|c|}{ Air transmission } \\
\hline $\log R$ & -1.522 & 0.3362 & -1.521 & 0.3261 \\
\hline
\end{tabular}

Description and unit of a parameter is explained in APPENDIX A.
The contribution of these variables to $Y_{c}$ was also obtained.

\section{Results and Discussion}

\subsection{Hand Assessment}

Table 3 shows the Pearson correlation coefficients of the 12 bipolar descriptors. A strong dependence of overall comfort on fabric soft/hard, smooth/rough and $\mathrm{rigid} / \mathrm{drapable}$ is observed for both the summer and winter surveys. These three descriptors were also highly correlated with each other. Low negative correlations found between clammy/absorbent, clingy/flowing, crushable/resilient, natural/synthetic, lacy/plain and overall comfort. Pearson correlation coefficients between natural/synthetic and crushable/ resilient are 0.809 for the summer and 0.723 for the winter. It seems that consumers thought that fabrics made from synthetic fibers were more resilient than those from natural fibers. It was also seen that the correlation coefficient between natural/synthetic and clingy/flowing are -0.847 for summer and -0.843 for winter. This result may reflect consumer's under. standing that synthetic fiber produces more elec. trostatic property than natural fiber during wearing.

It has been reported that the overall comfort of the lining used for ladies' garments is mostly related to thermal properties [15]. In this trial, the correlation coefficients between cool/warm and comfort/discom. fort were -0.762 for summer and -0.622 for winter.

Low Pearson correlation coefficients were obtained between overall sensorial comfort rating and some de. scriptors which related to the wearing performance viz. clammy/absorbent, clingy/flowing, crushable/resilient. These results showed the limitation of hand assessment to evaluate overall comfort and these properties can be evaluated only by the actual wear. ing test.

Principal factor analysis was applied to understand the common concept of sensorial overall comfort for subjects based on the hand assessment. The rotation varimax method was then applied to the four factors those eigenvalues were more than 1.0 . The results are shown in Table 4-a for the summer and Table 4-b for the winter survey. In the summer survey, the first factor was mainly concerned with the mechanical and surface properties. The second factor was related to 
Table 3 The Correlation Coefficients of the 12 Bipolar Descriptors

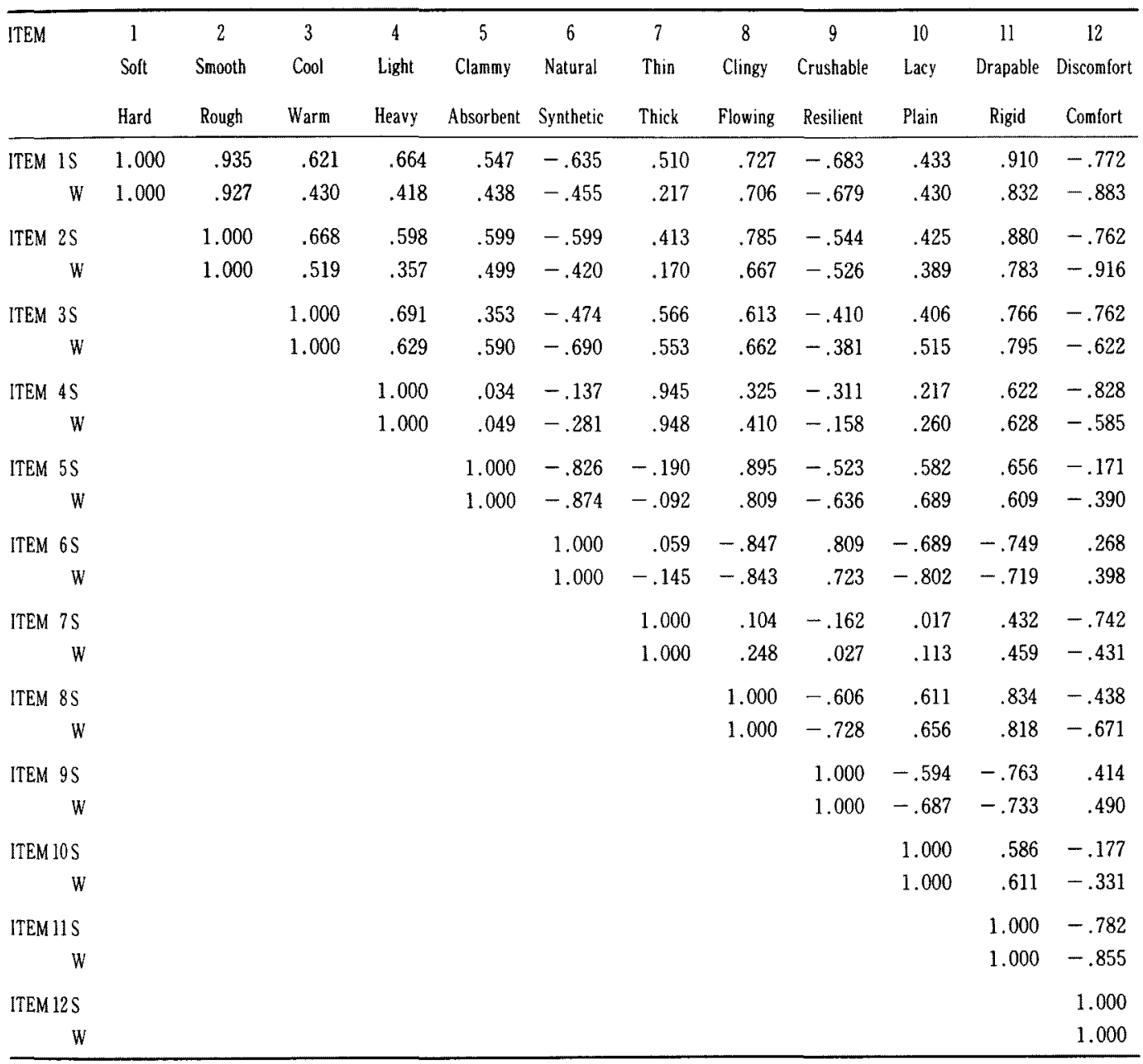

S: summer $\mathrm{W}$ : winter

the fabric thickness and weight. The third factor included such items as natural/synthetic, crushable/resilient and lacy/plain. In the winter survey, the first factor includes natural/synthetic, clammy/absorbent, clingy/flowing, crushable/resilient, lacy/plain which were mainly concerned with the performance during wearing. The second factor was related to mechanical properties and the third factor was thickness and weight.

For the evaluation of sensorial overall comfort, our hypothesis was that comfort might be evaluated from two groups of properties. One related to the fabric mechanical, surface and thermal properties which could be detected directly by hands. Others such as clingy, absorbent, crushable properties were considered to be related to wearing performance. Both properties can be predicted from the mechanical, surface and thermal properties obtained from hands and also from the subject's experience. The results obtained by the winter survey seemed to agree to our hypothesis. However, it was seen in the summer survey that some descriptors related to the wearing performance (clammy/absorbent, clingy/flowing) were included with fabric mechanical and surface properties in the first factor. This results showed some interaction between these two group of properties.

The three fabrics that scored highest (T20, T21, $\mathrm{T} 33)$ and the lowest (T12, T14, T31) in overall com. 
Table 4-a Rotated Factor Pattern (Summer)

\begin{tabular}{l|ccc}
\hline & Factor 1 & Factor 2 & Factor 3 \\
1 Soft-Hard & $0.70 *$ & 0.56 & 0.32 \\
2 Smooth-Rough & $0.81 *$ & 0.47 & 0.21 \\
3 Cool-Warm & 0.40 & $0.63 *$ & 0.30 \\
4 Light-Heavy & 0.17 & $0.95 *$ & 0.10 \\
5 Clammy-Absorbent & $0.75 *$ & -0.20 & 0.51 \\
6 Natural-Synthetic & -0.57 & 0.02 & $-0.77 *$ \\
7 Thin-Thick & -0.01 & $0.96 *$ & -0.06 \\
8 Clingy-Flowing & $0.79 *$ & 0.11 & 0.51 \\
9 Crushable-Resilient & -0.33 & -0.25 & $-0.78 *$ \\
10 Lacy-Plain & 0.23 & 0.07 & $-0.77 *$ \\
11 Drapable-Rigid & $0.66 *$ & 0.51 & 0.51 \\
\hline Eigenvalue & 3.441 & 3.130 & 2.846 \\
Contribution ratio $\%)$ & 60.9 & 22.4 & 8.0 \\
\hline
\end{tabular}

Final communality estimates: Total $=9.417$

Note: Items that define factors are flagged by an "*".

Table 4-b Rotated Factor Pattern (Winter)

\begin{tabular}{l|ccc}
\hline & Factor 1 & Factor 2 & Factor 3 \\
1 Soft-Hard & 0.29 & $0.92 *$ & 0.18 \\
2 Smooth-Rough & 0.25 & $0.92 *$ & 0.13 \\
3 Cool-Warm & 0.57 & 0.25 & 0.57 \\
4 Light-Heavy & 0.11 & 0.23 & $0.95 *$ \\
5 Clammy-Absorbent & $0.87 *$ & 0.26 & -0.11 \\
6 Natural-Synthetic & $-0.95 *$ & -0.17 & -0.15 \\
7 Thin-Thick & -0.01 & 0.05 & $0.97 *$ \\
8 Clingy-Flowing & $0.75 *$ & 0.49 & 0.22 \\
9 Crushable-Resilient & $-0.71 *$ & -0.48 & 0.02 \\
10 Lacy-Plain & $0.80 *$ & 0.17 & 0.12 \\
11 Drapable-Rigid & 0.58 & $0.64 *$ & 0.46 \\
\hline Eigenvalue & 4.177 & 2.822 & 2.522 \\
Contribution ratio $(\%)$ & 61.4 & 18.4 & 11.6 \\
\hline
\end{tabular}

Final communality estimates: Total $=9.521$

Note: Items that define factors are flagged by an "*".

fort were in both the summer and winter surveys and were selected for further analysis. Average values of 12 bipolar attributes for each of the six fabrics are plotted in Fig. 2. Effective differences between most comfortable and least comfortable fabrics occurs for bipolar descriptors soft/hard, smooth/rough, light/ heavy, thin/thick and drapable/rigid. It has been found that consumers regarded very soft and smooth. relatively light weight more resilient and much more drapable fabrics as more comfortable for lingerie.

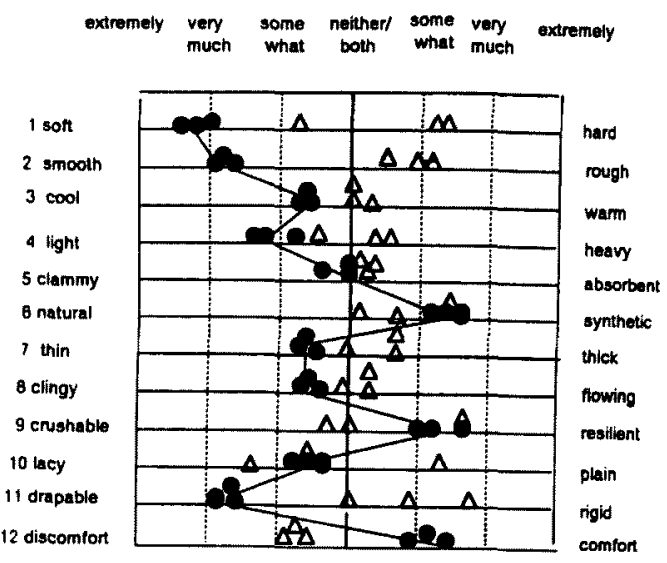

Fig. 2 Subjective ratings for the fabrics having the three highest scores $(O)$ and the lowest $(\Delta)$ in overall comfort.

\subsection{The Relationship between Subjective Judgment and Mechanical, Surface and Thermal Properties}

The multiple correlation coefficients $R_{c}$ from the stepwise block regression analysis for eleven items are shown in Table 5 -a and Table 5-b. The accuracy of the prediction increases with an increasing number of blocks but the accuracy almost saturates after three or four steps. The compression property (LC, $\mathrm{WC}, \mathrm{RC}$ ) enters as the first block in the regression equation for the following items of both summer and winter surveys; smooth/rough, clammy/absorbent, natural/synthetic, clingy/flowing, crushable/resilient, lacy/plain. drapable/rigid. The water, heat, air trans. mission properties and the surface characteristics represent the important parameter for the prediction of soft/hard feeling in the summer survey.

Constants $C_{i}$ in equation (1) represent the contribution of parameters $X_{i}$ to subjective value $Y_{s}$. Constants $C_{i}$ and the multiple correlation coefficients, $R_{c}$ for items which were highly correlated with overall comfort are shown in Table 6-a and 6-b. In these Tables, positive values indicate that each parameter contributes to the quality becoming more hard, rough, warm or rigid. The most contributed parameter in compression to such items as viz. smooth/rough and drapable/rigid was found to be WC (energy in compressing fabric) in this Table. For soft/hard feeling in the summer survey, the increase of $Q_{w c}, K, C$, and the 
Table 5-a Multiple Correlation Coefficients Rc from the Stepwise Block Regression Analysis for the Summer Survey

\begin{tabular}{|c|c|c|c|c|c|c|c|}
\hline & Step 1 & Step 2 & Step 3 & Step 4 & Step 5 & Step 6 & Step 7 \\
\hline \multirow[t]{2}{*}{ lien 1} & $Q_{w C}, K, C, R$ & MIU, MMD, SMD & LT, WT, RT & $L C, W C, R C$ & G. $2 \mathrm{HG}$ & T. W & $\mathrm{B}, 2 \mathrm{HB}$ \\
\hline & 0.69 & 0.76 & 0.80 & 0.85 & 0.86 & 0.87 & 0.87 \\
\hline \multirow[t]{2}{*}{ Iten 2} & LC, WC, RC & $L T, W T, R T$ & $Q_{\text {wa }}, K, C, R$ & MU, MMD, SMD & $\mathrm{G}, 2 \mathrm{HG}$ & $T, W$ & B. $2 \mathrm{HB}$ \\
\hline & 0.76 & 0.80 & 0.83 & 0.84 & 0.84 & 0.85 & 0.85 \\
\hline \multirow[t]{2}{*}{ Item 3} & $Q_{w C}, K, C, R$ & $\mathrm{LC}, \mathrm{WC}, \mathrm{RC}$ & $\mathrm{B}, 2 \mathrm{HB}$ & LT, WT, RT & MIU, MMD, SMD & $\mathrm{G}, 2 \mathrm{HG}$ & $\tau, W$ \\
\hline & 0.85 & 0.90 & 0.91 & 0.91 & 0.91 & 0.91 & 0.91 \\
\hline \multirow[t]{2}{*}{ ltem 4} & $Q_{W C}, K ; C, R$ & LT, WT, RT & $T, W$ & $\mathrm{LC}, \mathrm{WC}, \mathrm{RC}$ & $\mathrm{MIU}, \mathrm{MMD}, \mathrm{SMD}$ & $\mathrm{G}, 2 \mathrm{HG}$ & B, 2HB \\
\hline & 0.75 & 0.81 & 0.85 & 0.86 & 0.88 & 0.89 & 0.89 \\
\hline \multirow[t]{2}{*}{ Item 5} & $L C, W C, R C$ & MUU, MMD, SMD & LT, WT, RT & $Q_{W C}, K, C, R$ & $\mathrm{~B}, 2 \mathrm{HB}$ & $T, W$ & $\mathrm{G}, 2 \mathrm{HG}$ \\
\hline & 0.75 & 0.82 & 0.84 & 0.86 & 0.87 & 0.88 & 0.88 \\
\hline \multirow[t]{2}{*}{ ltem 6} & $L C, W C, R C$ & MU, MMD, SMD & $Q_{w c}, K, C, R$ & LT, WT, RT & $\mathrm{T}, \mathrm{W}$ & G, $2 \mathrm{HC}$ & $\mathrm{B}, 2 \mathrm{HB}$ \\
\hline & 0.71 & 0.83 & 0.85 & 0.86 & 0.87 & 0.88 & 0.89 \\
\hline \multirow[t]{2}{*}{ Item 7} & $Q_{W C}, K, C, R$ & MIU, MMD, SMD & LC, WC, RC & $\mathrm{G}, 2 \mathrm{HG}$ & $\mathrm{B}, 2 \mathrm{HB}$ & T. W & LT, WT, RT \\
\hline & 0.74 & 0.81 & 0.84 & 0.86 & 0.87 & 0.88 & 0.88 \\
\hline \multirow[t]{2}{*}{ Ltem 8} & $L C, W C, R C$ & LT, WT, RT & MIU, MMD, SMD & $Q_{w c}, K, C, R$ & $T, W$ & $\mathrm{~B}, 2 \mathrm{HB}$ & $\mathrm{G}, 2 \mathrm{HG}$ \\
\hline & 0.84 & 0.89 & 0.90 & 0.91 & 0.91 & 0.92 & 0.92 \\
\hline \multirow[t]{2}{*}{ Iten 9} & LC, WC, RC & LT, WT, RT & B. $2 \mathrm{HB}$ & $Q_{H C}, K^{\prime}, C, R$ & $L T, W T, R T$ & $T, W$ & $0,2 H G$ \\
\hline & 0.55 & 0.74 & 0.83 & 0.85 & 0.86 & 0.87 & 0.87 \\
\hline \multirow[t]{2}{*}{ Item 10} & LC, WC, RC & MIU, MMD, SMD & $T, W$ & $Q_{w C}, K, C, R$ & LT, WT, RT & $\mathrm{B}, 2 \mathrm{HB}$ & G. $2 \mathrm{HG}$ \\
\hline & 0.55 & 0.74 & 0.79 & 0.81 & 0.82 & 0.82 & 0.82 \\
\hline \multirow[t]{2}{*}{ Item II } & LC, WC, RC & LT, WT, RT & Quc, $K, C, R$ & MIU, MMD, SMD & $\mathrm{G}, 2 \mathrm{HG}$ & $\mathrm{B}, 2 \mathrm{HB}$ & $T, W$ \\
\hline & 0.82 & 0,88 & 0.89 & 0.92 & 0.93 & 0.93 & 0.93 \\
\hline
\end{tabular}

Table 5-b Multiple Correlation Coefficients Re from the Stepwise Block Regression Analysis for the Winter Survey

\begin{tabular}{|c|c|c|c|c|c|c|c|}
\hline & Step 1 & Step 2 & Step 3 & Step 4 & Step 5 & Step 6 & Step 7 \\
\hline \multirow[t]{2}{*}{ Iten 1} & LC, WC, RC & LT, WT, RT & MIU, MMD, SMD & $\mathrm{G}, 2 \mathrm{HG}$ & $Q_{w E}, K, C, R$ & T. W & B. $2 \mathrm{HB}$ \\
\hline & 0.60 & 0.73 & 0.78 & 0.80 & 0.81 & 0.81 & 0.81 \\
\hline \multirow[t]{2}{*}{ litem 2} & $L C, W C, R C$ & LT, WT, RT & MU, MMD, SMD & $Q_{W C}, K, C, R$ & B, 2HB & $\mathrm{G}, 2 \mathrm{HG}$ & $\mathrm{T}, \mathrm{W}$ \\
\hline & 0.67 & 0.73 & 0.83 & 0.78 & 0.79 & 0.79 & 0.79 \\
\hline \multirow[t]{2}{*}{ Item 3} & $Q_{w C}, K, C, R$ & $\mathrm{~B}, 2 \mathrm{HB}$ & MIU, MMD, SMD & $L C, W C, R C$ & $\mathrm{G}, 2 \mathrm{HG}$ & LT, WT, RT & $T, W$ \\
\hline & 0.91 & 0.93 & 0.94 & 0.95 & 0.95 & 0.95 & 0.95 \\
\hline \multirow[t]{2}{*}{ Item 4} & $Q_{w C}, K: C, R$ & $T, W$ & LT, WT, RT & $\mathrm{B}, 2 \mathrm{HB}$ & $\mathrm{G}, 2 \mathrm{HG}$ & MIU, MMD, SMD & LC, WC, RC \\
\hline & 0.74 & 0.80 & 0.84 & 0.86 & 0.88 & 0.88 & 0.88 \\
\hline \multirow[t]{2}{*}{ Item 5} & LC, WC, RC & B. 2HB & $Q_{W C}, K^{\prime}, C, R$ & MIU, MMD, SMD & LT, WT, RT & $\mathrm{G}, 2 \mathrm{HG}$ & $T, W$ \\
\hline & 0.36 & 0.81 & 0.82 & 0.83 & 0.83 & 0.83 & 0.83 \\
\hline \multirow[t]{2}{*}{ lien 6} & $L C, W C, R C$ & $Q_{W C}, K, C, R$ & MIU, MMD, SMD & LT, WT, RT & $T, W$ & B, $2 \mathrm{HB}$ & $\mathrm{G}, 2 \mathrm{HC}$ \\
\hline & 0.77 & 0.83 & 0.86 & 0.86 & 0.87 & 0.87 & 0.87 \\
\hline \multirow[t]{2}{*}{ Item 7} & $Q_{W C}, K^{\prime}, C_{1} R$ & MIU, MMD, SMD & $T, W$ & $\mathrm{~B}, 2 \mathrm{HB}$ & G. $2 \mathrm{HG}$ & LT, WT, RT & $\mathrm{LC}, \mathrm{WC}, \mathrm{RC}$ \\
\hline & 0.72 & 0.79 & 0.81 & 0.83 & 0.84 & 0.84 & 0.84 \\
\hline \multirow[t]{2}{*}{ Jtem 8} & $L C, W C, R C$ & LT, WT, RT & MU, MMD, SMD & $Q_{w C}, K, C, R$ & $T, W$ & B. $2 \mathrm{HB}$ & $\mathrm{G}, 2 \mathrm{HG}$ \\
\hline & 0.80 & 0.85 & 0.86 & 0.87 & 0.87 & 0.87 & 0.87 \\
\hline \multirow[t]{2}{*}{ Iten 9} & LC, WC, RC & MUU, MMD, SMD & LT, WT, RT & $Q_{W C}, K, C, R$ & $T, W$ & $\mathrm{G}, 2 \mathrm{HG}$ & $\mathrm{B}, 2 \mathrm{HB}$ \\
\hline & 0.60 & 0.78 & 0.81 & 0.82 & 0.83 & 0.83 & 0.83 \\
\hline \multirow[t]{2}{*}{ Item 10} & LC, WC, RC & MIU, MMD, SMD & $T, W$ & $L T, W T, R T$ & $Q_{\text {inc, }}, K^{\prime}, C, R$ & B, $2 \mathrm{HB}$ & $\mathrm{G}, 2 \mathrm{HG}$ \\
\hline & 0.60 & 0.77 & 0.83 & 0.84 & 0.85 & 0.85 & 0.85 \\
\hline \multirow[t]{2}{*}{ Iten 11} & $\mathrm{LC}, \mathrm{WC}, \mathrm{RC}$ & LT, WT, RT & $Q_{\text {uic }}, K, C, R$ & MIU, MMD, SMD & $\mathrm{G}, 2 \mathrm{HG}$ & $\mathrm{B}, 2 \mathrm{HB}$ & $T, W$ \\
\hline & 0.82 & 0.87 & 0.89 & 0.91 & 0.92 & 0.93 & 0.93 \\
\hline
\end{tabular}


Table 6-a Constants, $C_{i}$ and the Multiple Correlation. $R_{c}$ To Explain the Soft/Hard and Smooth/Rough Feeling

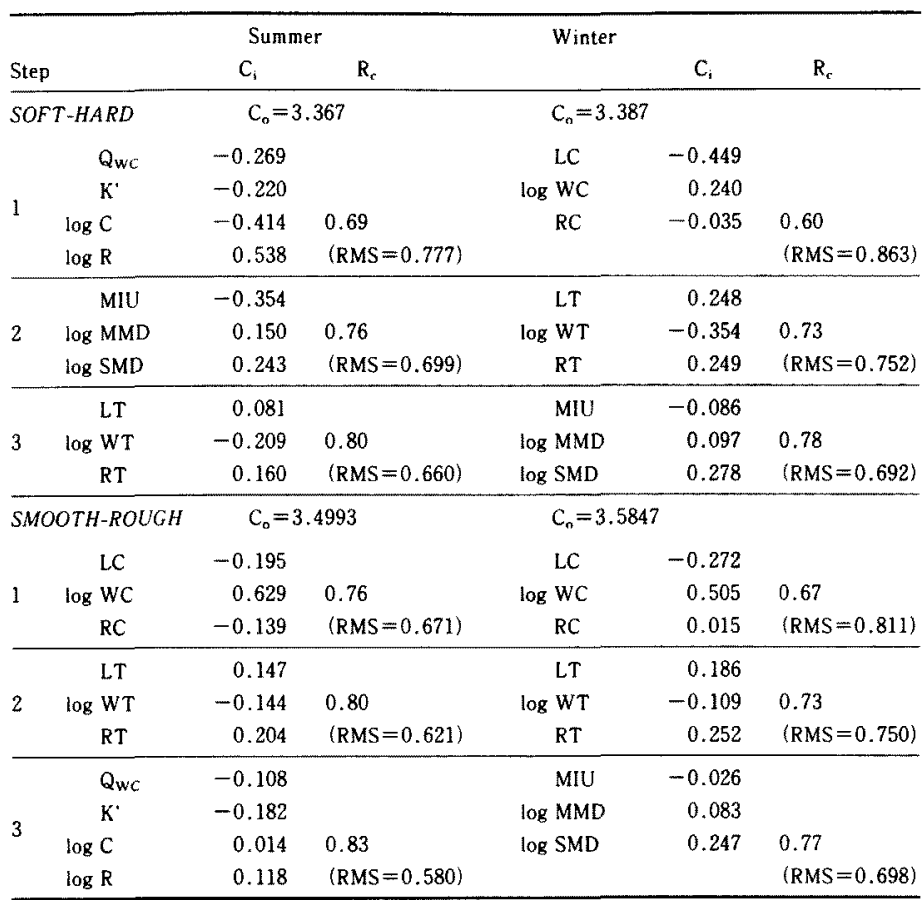

RMS: root mean square of regression error.

Table 6-b Constants, $C_{1}$ and the Multiple Correlation Coefficients, $R_{c}$ To Explain the Cool/Warm and Drapable/Rigid Feeling

\begin{tabular}{|c|c|c|c|c|c|c|}
\hline & & Sumn & & Winte & & \\
\hline St & & $\mathrm{C}_{\mathrm{i}}$ & $\mathbf{R}_{\mathrm{r}}$ & & $C_{i}$ & $\mathrm{R}_{c}$ \\
\hline & $L-W A R M$ & $C_{0}=$ & 2342 & $C_{0}=4$ & & \\
\hline & $Q_{W c}$ & -0.220 & & $Q_{w c}$ & -0.306 & \\
\hline 1 & $K^{\prime}$ & -0.168 & & $K^{\prime}$ & -0.171 & \\
\hline 1 & $\log C$ & -0.166 & 0.85 & $\log C$ & -0.202 & 0.91 \\
\hline & $\log R$ & 0.146 & $(\mathrm{RMS}=0.278)$ & $\log R$ & 0.063 & $($ RMS $=0.263)$ \\
\hline & LC & -0.222 & & $\log B$ & 0.116 & \\
\hline 2 & $\log W C$ & -0.121 & 0.90 & $\log 2 \mathrm{HB}$ & -0.004 & 0.93 \\
\hline & $\mathrm{RC}$ & 0.009 & $(\mathrm{RMS}=0.231)$ & & & $(\mathrm{RMS}=0.237)$ \\
\hline & $\log B$ & -0.038 & & $\mathrm{MIU}$ & -0.096 & \\
\hline 3 & $\log 2 \mathrm{HB}$ & 0.081 & 0.91 & $\log \mathrm{MMD}$ & 0.037 & 0.94 \\
\hline & & & $(\mathrm{RMS}=0.223)$ & $\log S M D$ & 0.096 & $($ RMS $=0.210)$ \\
\hline & $P A B L E-R I G I D$ & $C_{0}=$ & 7395 & $C_{n}=3$ & & \\
\hline & LC & -0.196 & & LC & -0.286 & \\
\hline 1 & $\log W C$ & 0.593 & 0.82 & $\log W C$ & 0.574 & 0.82 \\
\hline & $\mathrm{RC}$ & -0.161 & $(\mathrm{RMS}=0.529)$ & $\mathrm{RC}$ & -0.044 & $(\mathrm{RMS}=0.567)$ \\
\hline & LT & 0.158 & & $L T$ & 0.199 & \\
\hline 2 & $\log W T$ & -0.295 & 0.88 & $\log \mathrm{WT}$ & -0.287 & 0.87 \\
\hline & RT & 0.054 & $(\mathrm{RMS}=0.453)$ & RT & 0.021 & $(\mathrm{RMS}=0.50)$ \\
\hline & $\overline{Q w c}$ & -0.130 & & $Q_{w c}$ & -0.162 & \\
\hline 3 & $K^{\prime}$ & -0.031 & & $K^{\prime \prime}$ & 0.055 & \\
\hline 3 & $\log C$ & -0.071 & 0.89 & $\log C$ & -0.115 & 0.89 \\
\hline & $\log R$ & 0.104 & $($ RMS $=0.408)$ & $\log R$ & 0.090 & $(\mathrm{RMS}=0.457)$ \\
\hline
\end{tabular}

RMS: root mean square of regression error. 
Table 7 The Prediction of Sensorial Comfort

\begin{tabular}{|c|c|c|c|c|c|c|}
\hline Step & $\begin{array}{c}\text { Summer } \\
\text { parameter }\end{array}$ & $\mathrm{R}_{\mathrm{c}}$ & RMS & $\begin{array}{c}\text { Winter } \\
\text { parameter }\end{array}$ & $\mathrm{R}_{c}$ & RMS \\
\hline 1 & $Q_{w c}, K, C, R$ & 0.75 & 0.354 & $Q_{w c}, K, C, R$ & 0.78 & 0.363 \\
\hline 2 & MIU, MMD, SMD & 0.84 & 0.290 & MIU, MMD, SMD & 0.84 & 0.313 \\
\hline 3 & LT, WT, RT & 0.88 & 0.261 & $\mathrm{G}, 2 \mathrm{HG}$ & 0.89 & 0.271 \\
\hline 4 & LC, WC, RC & 0.90 & 0.236 & $L C, W C, R C$ & 0.90 & 0.250 \\
\hline 5 & $\mathrm{G}, 2 \mathrm{HG}$ & 0.91 & 0.220 & LT, WT, RT & 0.91 & 0.236 \\
\hline 6 & $\mathrm{~B}, 2 \mathrm{HB}$ & 0.92 & 0.214 & $\mathrm{~T}, \mathrm{~W}$ & 0.93 & 0.219 \\
\hline 7 & $T, W$ & 0.92 & 0.207 & $\mathrm{~B}, 2 \mathrm{HB}$ & 0.93 & 0.211 \\
\hline
\end{tabular}

\section{comiont}

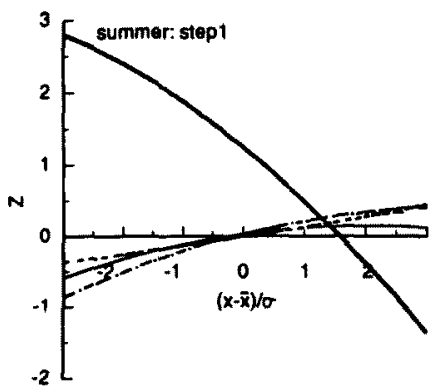

discomion

comton

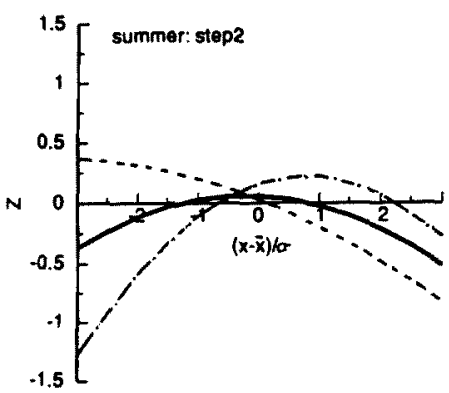

discomtort

Fig. 3-a The contribution of heat, water and air trans mission and surface characteristics to the comfort of lingerie fabrics for summer survey.

decrease of $R_{c}$ produced the increase of soft feeling.

Predicted sensorial comfort results are shown in Table 7. It was found that heat, water and air transmission characteristics and the surface characteristics represent the two most important properties for the prediction of overall fabric sensorial comfort. The contribution values, $Z$, are calculated by and plotted against $X_{i}$ for each water, air and thermal parameters in Fig. $3 \cdot a$ and also surface parameters in Fig. 3.b. It

\section{comion}
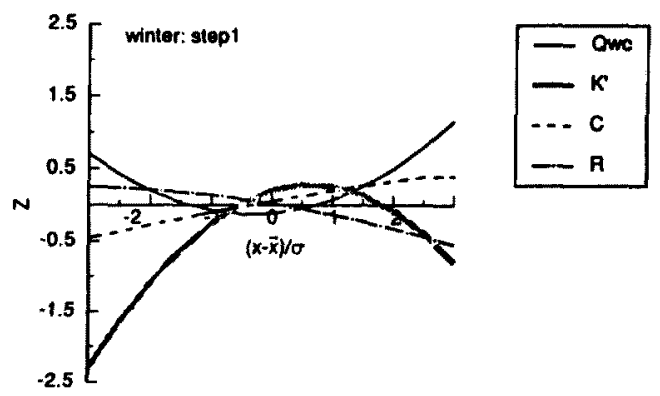

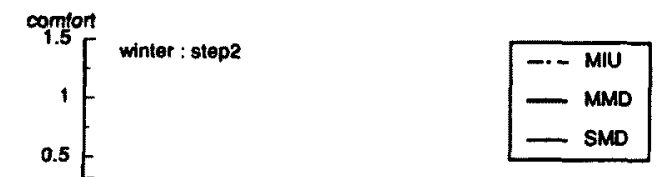

N

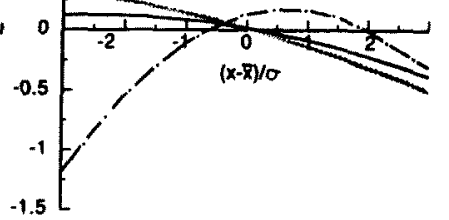

discomiort

Fig. 3-b The contribution of heat. water and air transmission and surface characteristics to the comfort of lingerie fabrics for winter survey.

can be seen in Fig. 3-a that the smaller values of air resistance $R$ represent a more comfortable feeling. This trend is easily observed in the summer survey results. The larger values of $C$, which means these fabrics felt cooler, represents a more comfortable feeling. For the winter results, values of $Q_{w c}, K^{\prime}$ show the optimum values to give a more comfortable feeling. We are not confident to say that properties such as $Q_{w c}, R$ can be evaluated by hands only. It might be 
considered that fabrics selected as more comfortable have higher values of heat conductance $K, C$ and low. er value of $\mathrm{R}$ than less comfortable fabrics. In Fig. 3 $b$, the smaller values of MMD give more comfort for both the summer and winter judgments. It is noted that the values of MIU reprensent the optimum range to contribute to the more comfortable feeling.

\section{Conciusion}

Sensorial overall comfort of lingerie fabrics was in. vestigated on the basis of hand assessment by con. sumers. Hand assessment revealed that consumers regarded fabrics, which were very soft and smooth, relatively light weight, more resilient and more drapable as more sensorially comfortable for lingerie than those that are judged hard, rough, heavy, crushable and rigid. Items which were highly correlated with sensorial overall comfort rating were soft/hard. smooth/rough, cool/warm and drapable/rigid. These characteristics were interpreted in terms of mechanical properties and heat and water transmission properties. Compression properties (LC, WC, RC) enters as the first block for the prediction of smooth/rough and drapable/rigid and the compression characteristic. WC, is one of the most important parameters.

Results of the stepwise regression analysis for the comfort/discomfort of fabrics, indicates that heat, water, air transmission properties and also surface characteristics of fabrics are important parameters for the prediction of fabric comfort/discomfort.

\section{Acknowledgement}

We greatly acknowledge Teijin Co. for providing useful samples and also for the financial support of this study. We would like to thank also Miss Yayoi Fukuhara and Miss Motoko Kato of Nara Women's University for their experimental work and Miss Hisako Yata of Niigata University for assistance in the hand assessment.

\section{References}

1. D. H. Branson, L. Abusamra, C. Hoener, and S. Rice, Text. Res. J., 58, 166 (1988).

2. H. Tokura and T. Midorikawa-Tsurutani, Text. Res. J., 55, 179 (1985).

3. N. R. S. Hollies, A. G. Custer, C. J. Morin, and M. E. Howard, Text. Res. J., 49, 557 (1979).

4. M. M. Sweeney and D. H. Branson, Text. Res. J., 60. 371 (1990).

5. R. N. Demartino, H. N. Yoon, A. Buckley, C. V. Evins. R. B. Averell, W. W. Jackson, D. C. Schultz, C. L. Becker, H. E. Booker, and N. R. S. Hollies, Text. Res. J., 54, 447 (1984).

6. R. N. Demartino, H. N. Yoo, and A. Buckley, Text. Res. J., 54, 602 (1984).

7. B. N. Hoschke, "Objective Specification of Fabric Quality, Mechanical Properties and Performance", (S. Kawabata, R. Postle and M. Niwa, Ed.), Text. Mach. Soc. Japan. p. 375 (1982).

8. R. Garnsworthy, R. Mayfield, R. Gully, R. Westerman, and P. Kenins, Proc. Int. Wool Text. Res. Conf., Tokyo, Vol. III, 190 (1985).

9. S. Kawabata, "The Standardization and Analysis of Hand Evaluation", HESC. Text. Mach. Soc. Japan, 2nd edition (1980).

10. H. Sakaguchi, M. Niwa, and S. Kawabata, J. Texi. Mach. Soc. Japan. 39. T33 (1986).

11. A. M. Fritz and A. P. W. Gardner, Proc. Text. Inst Annual World Conf. Sydney, 446 (1988).

12. "Sensory Evaluation Handbook", Research Committee of Sensory Evaluation, Ed., JUSE Press, p. 647 (1973).

13. S. Kawabata, J. Text. Mach. Soc. Japan. 37. T130 (1984).

14. S. Kawabata. M. Nakanishi, and M. Niwa, Sen'i Gakkai Symposia Preprints 1990(B), Sen'i Gakkai, B1 7 (1990).

15. H. Sakaguchi, M. Kato, and M. Niwa, J. Japan Res. Assoc. for Text. End-use, 26, 351 (1985).

APPENDIX A: Characteristic Values of Basic Mechanical Properties (13)

\begin{tabular}{ccc}
\hline $\begin{array}{c}\text { Parameter } \\
\text { symbol }\end{array}$ & Description & Unit \\
\hline $\begin{array}{c}\text { Tensile } \\
\mathrm{EM}\end{array}$ & Fabric extension at $5 \mathrm{~N} / \mathrm{cm}$ width & $\%$
\end{tabular}


LT

WT

RT

Shear

G

$2 \mathrm{HG}$

$2 \mathrm{HG} 3$

Bending

B

2HB

Surface

MIU

MMD

SMD

Compression

LC

WC

$\mathrm{RC}$

$\mathrm{T}$

Weight

Linearity of load extension curve

Energy in extending fabric to $5 \mathrm{~N} / \mathrm{cm}$ width

$\mathrm{J} / \mathrm{m}^{2}$

Tensile resilience

Shear rigidity

$\mathrm{N} / \mathrm{m}$

Hysteresis of shear force at $8.7 \mathrm{mrad}$

$\mathrm{N} / \mathrm{m}$

Hysteresis of shear force at $52.2 \mathrm{mrad}$

$\mathrm{N} / \mathrm{m}$

Bending rigidity

Hysteresis of bending moment

$\mu \mathrm{Nm}$

$\mathrm{mN}$

Coefficient of friction

Mean deviation of MIU

Geometrical roughness

$\mu \mathrm{m}$

Linearity of compression-thickness curve

Energy in compressing fabric under $5 \mathrm{kPa}$

Compressional resilience

$\mathrm{J} / \mathrm{m}^{2}$

Fabric thickness at $50 \mathrm{~Pa}$ pressure

$\%$

$\mathrm{mm}$

Mass per unit area

$\mathrm{mg} / \mathrm{m}^{2}$

APPENDIX B: Measurement Conditions of Heat, Water and Air Transport Properties

\begin{tabular}{|c|c|c|}
\hline Heat transport & & Unit \\
\hline $\mathrm{QD}_{c} \longrightarrow$ & $20^{\circ} \mathrm{C}, 65 \% \mathrm{RH}$ & $W /\left(\mathrm{m}^{2} \mathrm{~K}\right)$ \\
\hline $\mathrm{QD}_{\mathrm{s}}$ & Air velocity: $0.3 \mathrm{~m} / \mathrm{s}$ & $\mathrm{W} /\left(\mathrm{m}^{2} \mathrm{~K}\right)$ \\
\hline$Q_{w_{c}}$ & Temperature difference, $10^{\circ} \mathrm{C}$ & $W /\left(m^{2} K\right)$ \\
\hline$Q_{w s}-$ & & $\mathrm{W} /\left(\mathrm{m}^{2} \mathrm{~K}\right)$ \\
\hline$\lambda$ & contact pressure: $490 \mathrm{~Pa}$ & $W /\left(\mathrm{m}^{2} \mathrm{~K}\right)$ \\
\hline $\mathrm{K}^{\prime}$ & & $W /\left(m^{2} \mathrm{~K}\right)$ \\
\hline \multirow[t]{5}{*}{$\mathrm{C}$} & $\mathrm{C}=\mathrm{U}_{\mathrm{tm}} / \mathrm{U}_{\mathrm{r}}$ & \\
\hline & $\begin{array}{l}\text { Utm: peak value of the rate of the temperature } \\
\text { change at the receptor }\end{array}$ & ${ }^{\circ} \mathrm{C} / \mathrm{s}$ \\
\hline & Temperature difference, $\mathrm{U}_{\mathrm{r}}=10^{\circ} \mathrm{C}$ & $s^{-1}$ \\
\hline & contact pressure $.1 .47 \mathrm{kPa}$ & \\
\hline & contact speed $\quad .1 \mathrm{~cm} / \mathrm{s}$ & \\
\hline \multicolumn{3}{|l|}{ Air transport } \\
\hline $\mathrm{R}$ & $\begin{array}{l}\text { Differential pressure method under a constant rate } \\
\text { of } 0.04 \mathrm{~m} / \mathrm{s} \text {. }\end{array}$ & $\mathrm{kPa} \cdot \mathrm{s} / \mathrm{m}$ \\
\hline
\end{tabular}

